\title{
Recycling of End of Life Concrete Fines into Hardened Cement and Clean Sand
}

\author{
Somayeh Lotfi*, Peter Rem \\ Department of Materials and Environment, Delft University of Technology, Delft, Netherlands \\ Email: *s.lotfi@tudelft.nl
}

Received 22 March 2016; accepted 21 May 2016; published 24 May 2016

Copyright (C) 2016 by authors and Scientific Research Publishing Inc.

This work is licensed under the Creative Commons Attribution International License (CC BY). http://creativecommons.org/licenses/by/4.0/

(c) (i) Open Access

\begin{abstract}
One of the massive by-products of concrete to concrete recycling is the crushed concrete fines, that is often $0-4 \mathrm{~mm}$. Although the construction sector is to some extent familiar with the utilization of the recycled coarse fraction ( $>4 \mathrm{~mm}$ ), at present there is no high-quality application for fines due to its moisturized and contaminated nature. Here we present an effective recycling process on lab scale to separate the cementitious powder from the sandy part in the crushed concrete fines and deliver attractive products with the minimum amount of contaminants. For this study, a lab scale Heating-Air classification system was designed and constructed. A combination of heat and air classification, resulted in a proper separation of finer fraction $(0-0.250 \mathrm{~mm})$, from coarser fractions. Heating of the materials was followed by ball milling to enhance the liberation of the cementitious fraction. Experiments were carried out at different heating temperatures and milling durations. Experimental results show that by heating the materials to $500^{\circ} \mathrm{C}$ for 30 seconds, the required time of ball milling is diminished by a factor of three and the quality of the recycling products satisfies well the market demand. In addition, the removal of contaminants is complete at $500^{\circ} \mathrm{C}$. The amount of $\mathrm{CaO}$ in the recovered finer fraction from the recycling process is comparable with the amount of $\mathrm{CaO}$ in low-quality limestone. By using this fraction in the cement kiln as the replacement of limestone, the release of the chemically bound $\mathrm{CO}_{2}$ could be reduced by a factor of three.
\end{abstract}

\section{Keywords}

C2CA-Concrete Recycling, Recycled Concrete Fines, Recycled Cement, Recycled Hardened Cement

\section{Introduction}

The EU 28 countries currently generate 461 million tons per year of Construction and Demolition Waste (CDW)

${ }^{*}$ Corresponding author. 
with an average recycling rate of around 46\% [1]. According to the revised Waste Framework Directive (WFD), the minimum recycling percentage of non-hazardous CDW should be at least $70 \%$ by weight by 2020 [2]. End of life concrete is known to be the heaviest component of the CDW. By recycling part of the concrete fraction of $\mathrm{CDW}$ into high-quality construction materials such as aggregate, sand, and hardened cement, it is possible to get closer to the 2020 WFD goal. High-quality production and re-use of recycled aggregate are already well investigated and applied in countries like Netherlands, Belgium and Denmark [3]. Although concrete made with recycled aggregates is nowadays a practical reality in the building construction industry [4], the use of crushed concrete fines in new concrete production is still restricted in most standards. Crushed concrete fines is a massive fraction reaching the amount of 30 to $50 \mathrm{wt} \%$ of the whole mass of crushed concrete [5]. However, due to high water absorption, low density and the presence of impurities, its application is presently limited. Thus, there is a need for a proper recycling process to liberate sand from hardened cement existing in crushed concrete fines and decrease contaminant concentrations as far as possible.

\section{C2CA Concrete Recycling and Current Research Background}

The C2CA (Concrete to Cement and Aggregate) concrete recycling process aims at a cost-effective system approach for recycling high-volume End Of Life (EOL) concrete streams into prime-grade aggregates and cement (see Figure 1) [6].

The C2CA technologies include selective demolition to produce crushed concrete with a low level of contaminants, and mechanical upgrading of the material on-site into an aggregate product with sensor-based on-line

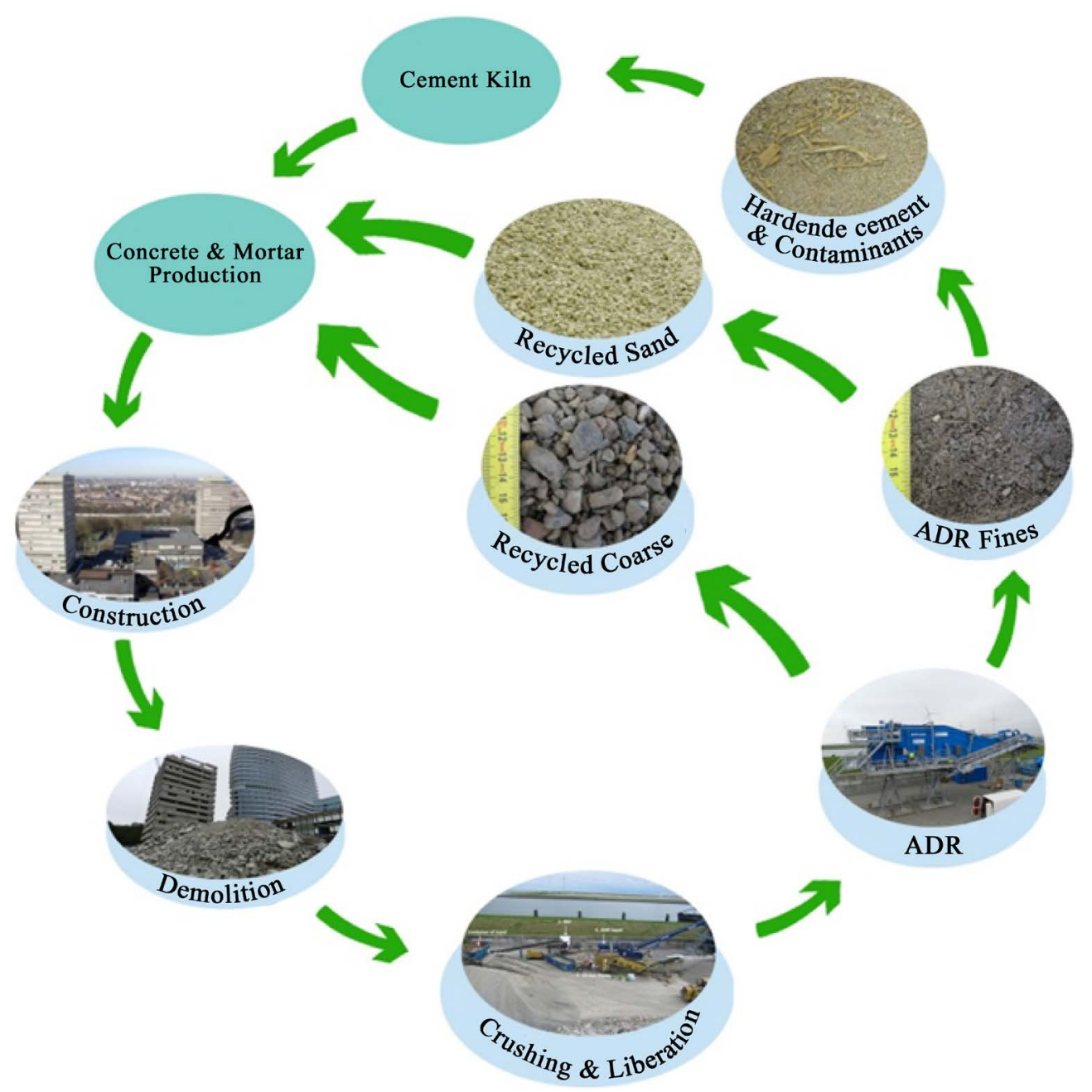

Figure 1. C2CA in brief. 
quality assurance and fines that can be processed (off-site) into Ca-rich material for new clinker production. In situ recycling of the aggregate is one of the primary goals of the C2CA. In the C2CA process, after crushing of EOL concrete, autogenous milling is used to remove the loose mortar from the surface of the aggregates. The removal of the loose mortar is important to improve the mechanical strength of the recycled aggregate [7]. After autogenous milling, a new low-cost classification technology, called Advanced Dry Recovery (ADR) is applied to remove the fines and light contaminants with an adjustable cut-point of between 1 and $4 \mathrm{~mm}$ for mineral particles. ADR uses kinetic energy to break the bonds that are formed by moisture and fine particles and can classify materials almost independent of their moisture content. After breaking up the material into a jet, the fine particles are separated from the coarse particles. ADR separation has the effect that the crushed concrete is concentrated into a coarse aggregate product and a fine fraction that includes the hardened cement, sand and light contaminants such as wood, plastics, and foams [6] [8] (see Figure 2).

To reduce cost and allow straightforward shipment of the produced recycled aggregate to a concrete production company, the $\mathrm{C} 2 \mathrm{CA}$ technology develops two types of sensors, hyper spectral imaging and laser induced breakdown spectroscopy, for automated online quality control and quality assurance [6] [10]-[12]. The concept is to avoid the need for laboratory analysis and intermediate storage, minimize transport of bulk materials and combine, if possible, quality and end-of-waste certification at the site, without human invention. A second major goal of $\mathrm{C} 2 \mathrm{CA}$, next to in situ processing and local reuse of the aggregate, is to help decrease $\mathrm{CO}_{2}$-emissions in cement production by concentrating part of the cement paste from EOL concrete into a separate fraction that can be reused as a low- $\mathrm{CO}_{2}$ feedstock replacing primary limestone. The Portland cement manufactory process is presently responsible for a large part of the global emission of $\mathrm{CO}_{2}$. It is estimated that the emission of carbon dioxide is at best around 0.87 ton for every ton of cement produced and the cement industry accounts for ca $10 \%$ of annual manmade $\mathrm{CO}_{2}$ emissions [13]. In this regard, there have been recently some attempts to use crushed concrete fines or ADR Fines (AF) as alternative low $\mathrm{CO}_{2}$ content input materials for the clinker production [14]-[16]. Within an industrial trial of the C2CA project for example, 600 tons of AF was successfully utilized in the industrial cement kiln of Heidelberg cement in the Netherlands to produce Portland cement. It is reported that the average amount of $\mathrm{CaO}$ and $\mathrm{SiO}_{2}$ in the utilized $\mathrm{AF}$ were $11.7 \%$ and $75.5 \%$ respectively. Although the produced cement from this trial was ranked as a high-quality one, still the goal of substantial $\mathrm{CO}_{2}$ reduction by replacing limestone with fines is not achieved. In the mentioned industrial-scale experiment, the maximum usage rate of AF was limited to $3.9 \mathrm{wt} \%$ due to its high sand content. Furthermore, in a recent study, Schoon et al. used AF as alternative raw material for Portland cement clinker production [14]. They also confirmed that AF could be used primarily as $\mathrm{SiO}_{2}$-sources in the cement kiln and by producing fines with higher $\mathrm{CaO}$ content it is possible to use it as limestone replacement. They demonstrated that the smaller fines fraction is cut from sand fraction, the better they are suited for Portland clinker production. Kwon et al. [16] and Gastaldi et al. [15] used hardened cement waste for new clinker production. In their experiments, they managed to make clinker applying hardened cement waste as low $\mathrm{CO}_{2}$ input material for the kiln. However, in both investigations it is concluded that an effective separation technology of cementitious powder from sand in crushed concrete fines is required.AF contains hardened cement, unliberated pieces of sand, moisture and light contaminants such as wood. In fact, the main problem with crushed concrete fines is associated with its contaminated and moisturized nature that also applies for AF.

The wet state of AF makes any dry separation process like screening or ball milling inefficient and costly while the contaminated nature of AF is the main concern for re-using it into new concrete. To deal with these problems, we aim to develop a combination of simultaneous heating, grinding and separation process to produce
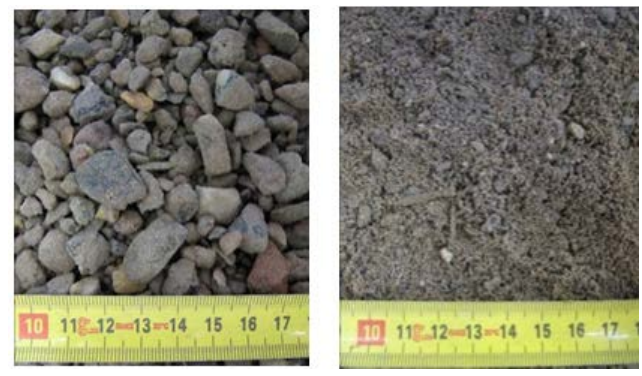

Figure 2. Products from crushed concrete by ADR: Coarse (left) and Fine (right) [9]. 
two main products: clean, dry sand ready for using in the concrete production and a concentration of cementitious powder with a very low amount of contaminants ready to sell as a minerals resource to the cement production companies. In this regard, the present study focuses on the lab-scale recycling of AF to hardened cement and sand using a combination of heating, air classification and grinding. Understanding the influence of heating temperature and grinding time on the hardened cement recovery is necessary for designing an industrial set-up for recycling of fines. This paper reports the effects of the process variables on the cement recovery, quality of the products and the level of the contaminants.

\section{Materials and Methods}

\subsection{0 - 4 mm ADR Fines (AF)}

The 0 - $4 \mathrm{~mm}$ ADR Fines (AF) were produced in a case study of the C2CA project that involved the demolition of a part of a governmental complex constructed from concrete based on CEMIII cement. Recycling of the EOL concrete from the complex was performed applying $\mathrm{C} 2 \mathrm{CA}$ technologies and the resulting $\mathrm{AF}$ was stored for further studies. The moisture content of AF was $12 \mathrm{wt} \%$.

\subsection{AF Recycling Set-Up}

The research set-up consists of a Heating-Air classification System (HAS) followed by grinding of materials using a Ball Mill (BM). HAS is made of an inclined pipe with a length of $600 \mathrm{~mm}$ (see the schematic of HAS in Figure 3). The internal and external diameters of the pipe are $11 \mathrm{~mm}$ and $20 \mathrm{~mm}$, respectively, and it is covered by a steel lid to avoid the dispersion of heat. For heating, three burners with a flame temperature of $1410^{\circ} \mathrm{C}$ were used. The temperature inside the pipe was measured by three thermocouples connected to a computer. To separate Finer Fraction (FF) which is mostly $0-0.25 \mathrm{~mm}$ from the Coarser Fraction (CF) which is mostly $0.25-4$ $\mathrm{mm}$, air classification is applied from the downer opening of the pipe. Thus, FF and light contaminants can be collected in a bin connected to the upper part of HAS. CF is led to a container connected to the down part of the pipe, and the whole system is installed on a vibrator to facilitate the materials movement inside the pipe. After heating the materials, the produced CF is milled using a ball mill. The ball mill used in this study has a mill chamber with a diameter of $600 \mathrm{~mm}$ and length of $300 \mathrm{~mm}$. The rotation speed was fixed at $45 \mathrm{rpm}$. Steel balls were put into the mill chamber to enhance the liberation of sand from cement powder. The balls to materials weight ratio was 2.5 and the diameter of the balls varied from 10 to $22 \mathrm{~mm}$ (see Figure 4).

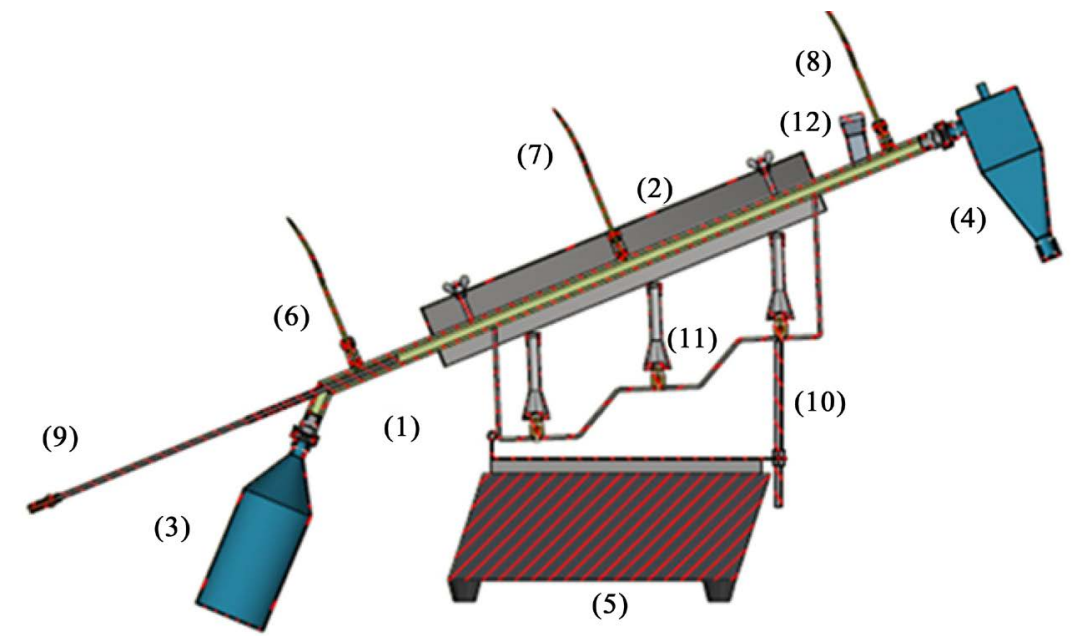
(1) Main pipe
(2) Steel cover
(3) Bin to collect coarse products
(4) Bin to collect fine products
(5) Vibrating device

(6), (7), (8) Thermocouples

(9) Blowing air

(10) Angle regulator

(11) Burners

(12) Materials feeder

Figure 3. HAS set-up to heat AF and separate finer fraction $(0-0.250 \mathrm{~mm})$ from coarser fraction $(0.250-4 \mathrm{~mm})$. 

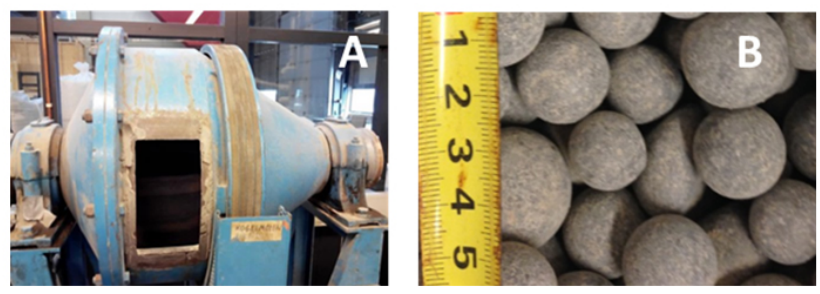

Figure 4. Applied lab-scale ball mill (A) and steel balls (B).

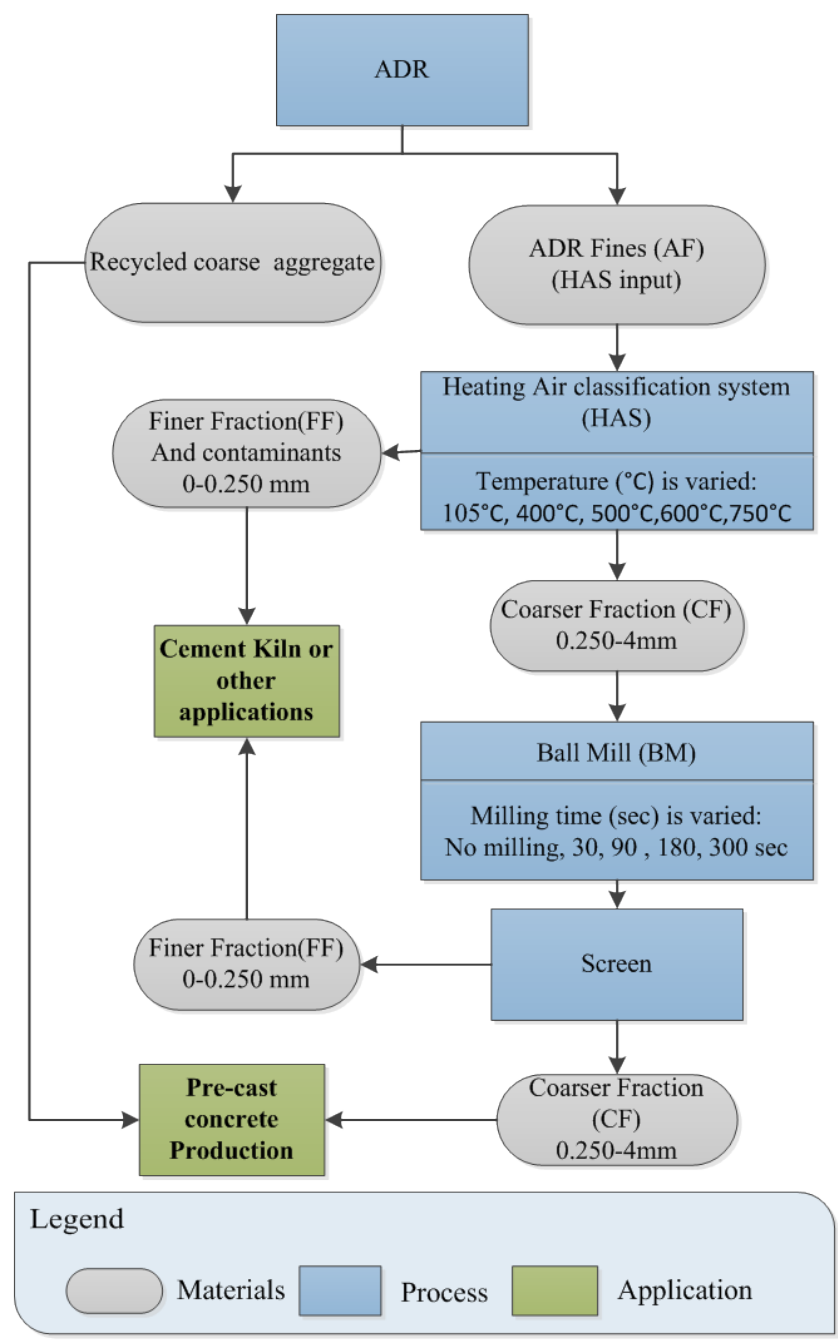

Figure 5. Flowchart of the recycling process.

\subsection{Experimental Design}

Experimental runs were carried out with varying temperature in HAS and residence time in BM. A variation of ball milling duration (time) and temperature in HAS resulted in a total of 20 different experimental conditions. Figure 5 gives a general overview of the recycling process. In addition, applied temperatures and ball milling durations are indicated in this figure. After each experimental run, particle size distribution of the produced samples was measured applying the sieving method. The sieving process was performed based on the standard EN 933-1. After sieving, the density of each fraction was determined. For measuring the density and avoiding the effects of inaccessible pores on the results, samples were firstly milled to powder smaller than $0.125 \mathrm{~mm}$. Afterwards, the densities were measured using a He pycnometer (model Accupyc 1330 Micromeritics). X-ray 
fluorescence (XRF) analysis was carried out on the same powders (size smaller than $0.125 \mathrm{~mm}$ ) to determine the chemical composition of the samples. For this analysis XRF (model PANalytical-Epsilon 3x spectrometers) was applied.

\section{Results and Discussion}

\subsection{Heating-Air Classification System (HAS) Performance}

For each experimental run, firstly the desired temperature along the heating pipe in HAS was attained. As it was shown in Figure 3 three thermocouples connected to the burners register the temperature at different points of the pipe. To conduct the experiments, the intensity of the middle burner was varied to reach the target temperature of the experimental design. Residence time of the materials along the HAS pipe was 30 seconds. After processing of the materials at different temperatures, the performance of the HAS was evaluated. Results presented very small deviations in particle size distributions of FF and CF coming from different heating temperature. The particle size distributions of the AF and two outputs (FF and CF) of HAS at $750^{\circ} \mathrm{C}$ are shown in Figure 6 as an example. With the multiplication of the cumulative passing percentage of FF and CF to their total mass percentage, following by the summation of the results, it is possible to reconstruct the cumulative passing distribution curve for input materials (shown as the control curve in Figure 7). A comparison between the control and HAS-input curves in Figure 7, shows that a limited amount of liberation (production of new particles) happened during the HAS processing. The recovery of each size fraction in FF and CF and the cut size point is shown in Figure 8. According to the figures, it is clear that while HAS heats the materials, it efficiently uses the air flow to separate FF and light contaminants from CF (see Figure 9). When concrete waste is heated, dehydration of cement accrues which could weaken the bonding strength between cement paste and aggregate. Thus, the possibility of preferential breakage along the boundaries between aggregate and cement paste increases [17]. Although using HAS, the bonding between hydrated cement and sand in CF is weakened; there is still a need to break this bond by means of an extra force which is provided by ball milling in the current study.

\subsection{Influence of Milling versus Heating}

To evaluate the effect of heat treatment and ball milling, experimental results were analyzed considering one variable (BM time or HAS temperature) at a time. Figure 10 shows the cumulative size distribution of materials

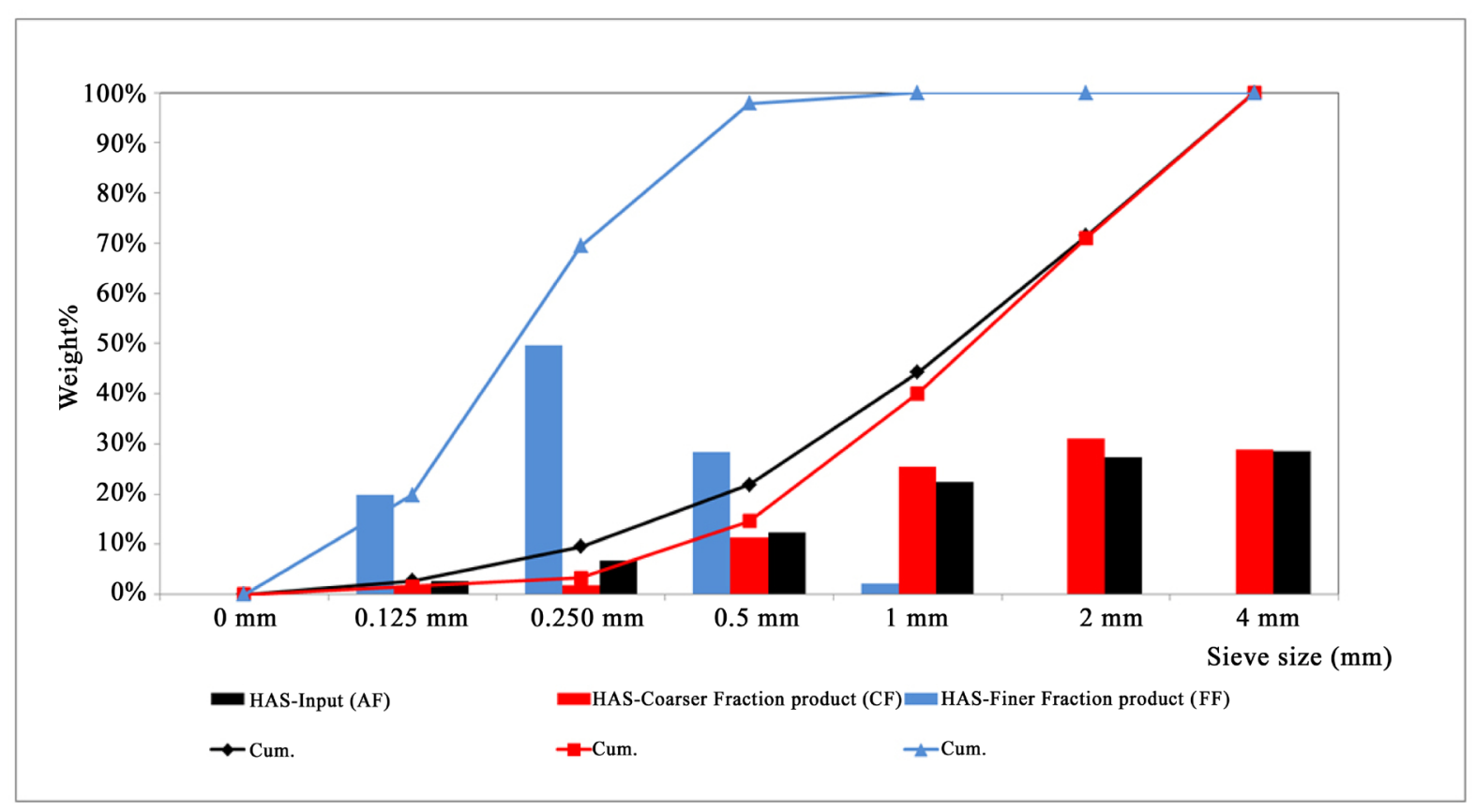

Figure 6. Particle size distribution of HAS input and outputs at $750^{\circ} \mathrm{C}$. The lines show the cumulative curves whereas the bars indicate the absolute fraction weights. 


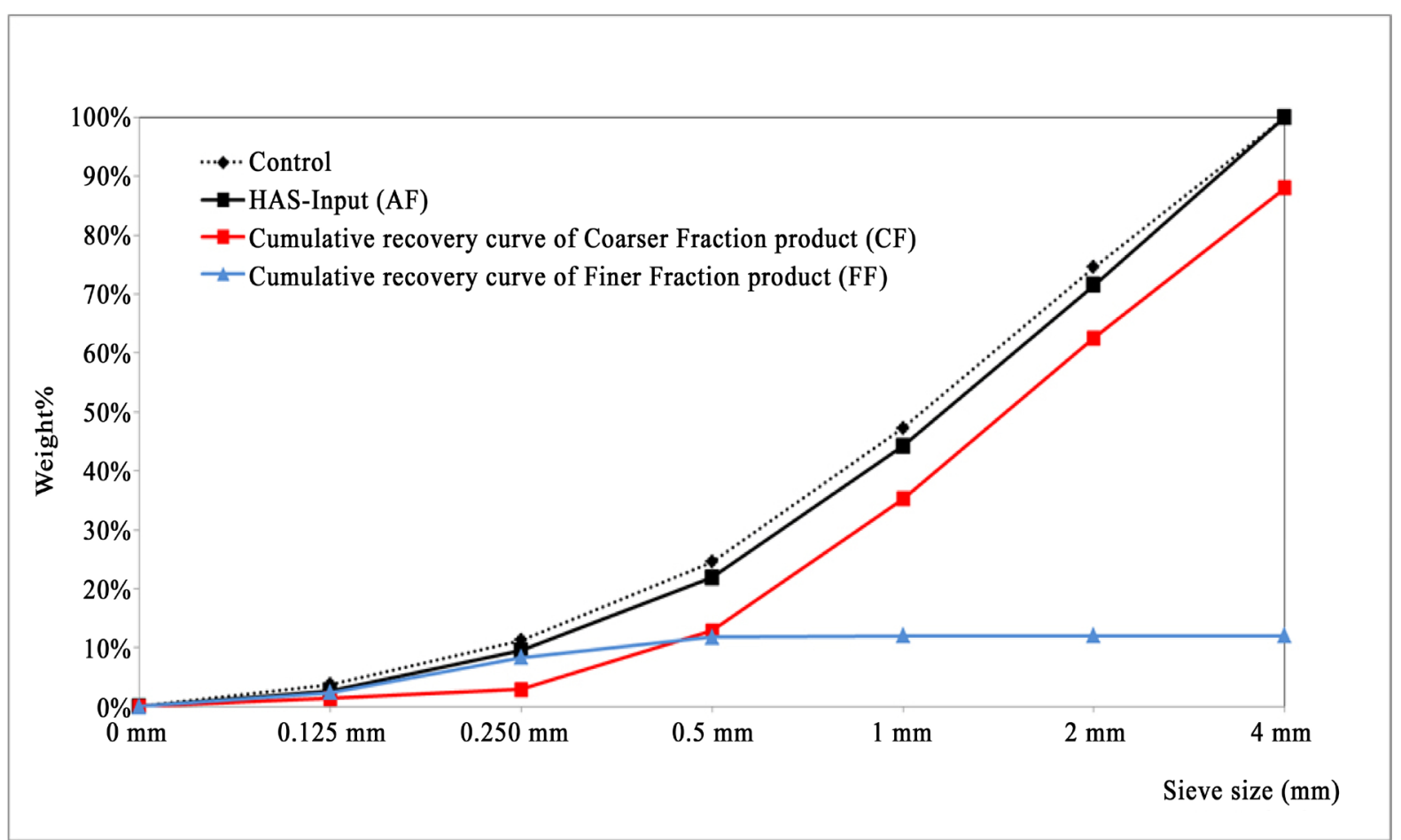

Figure 7. Reconstructed cumulative curve of the input materials (control curve) in comparison with the actual cumulative curve of HAS-Input.

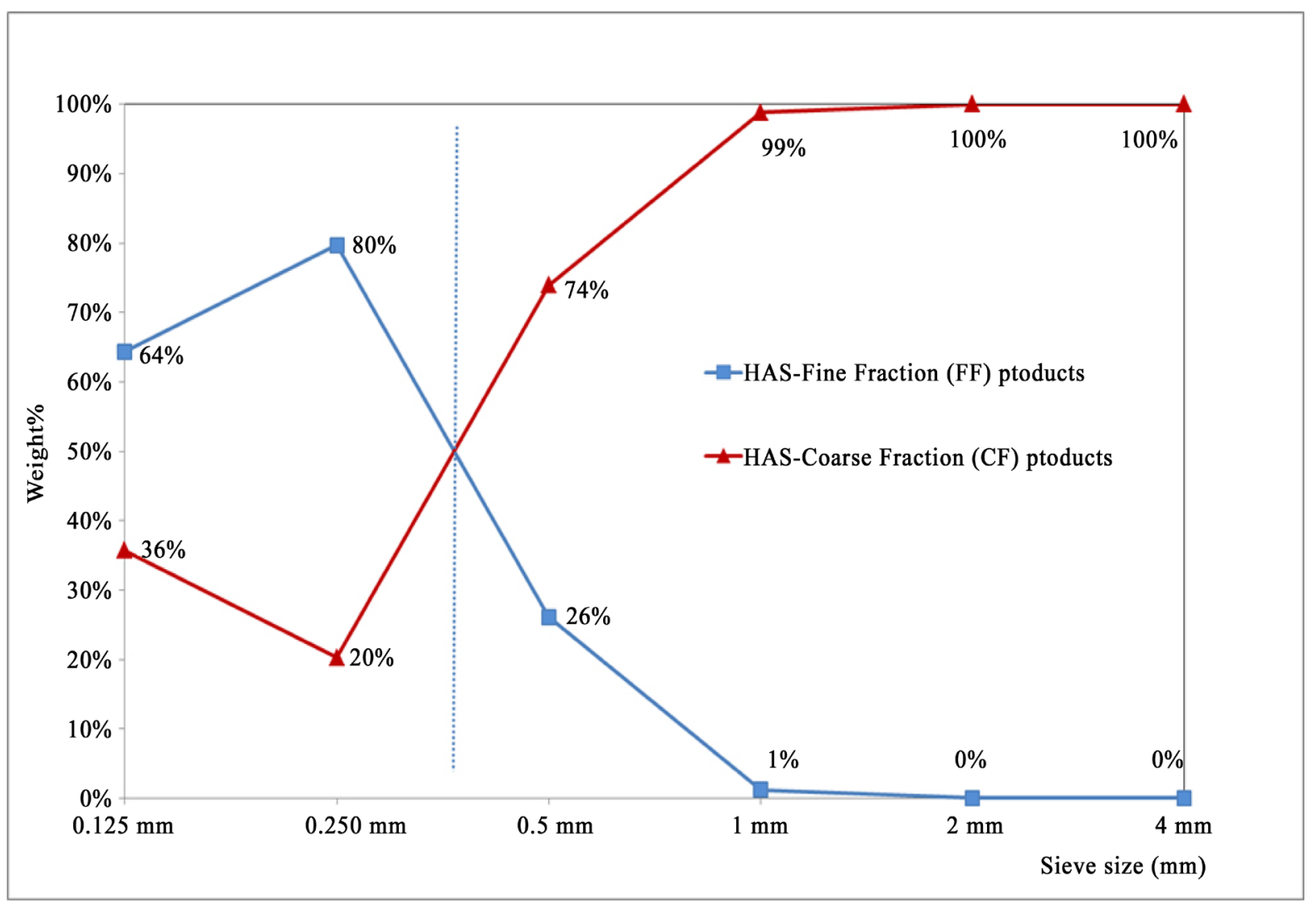

Figure 8. The recovery percentage of each size fraction into the two products of the HAS at $750^{\circ} \mathrm{C}$. 


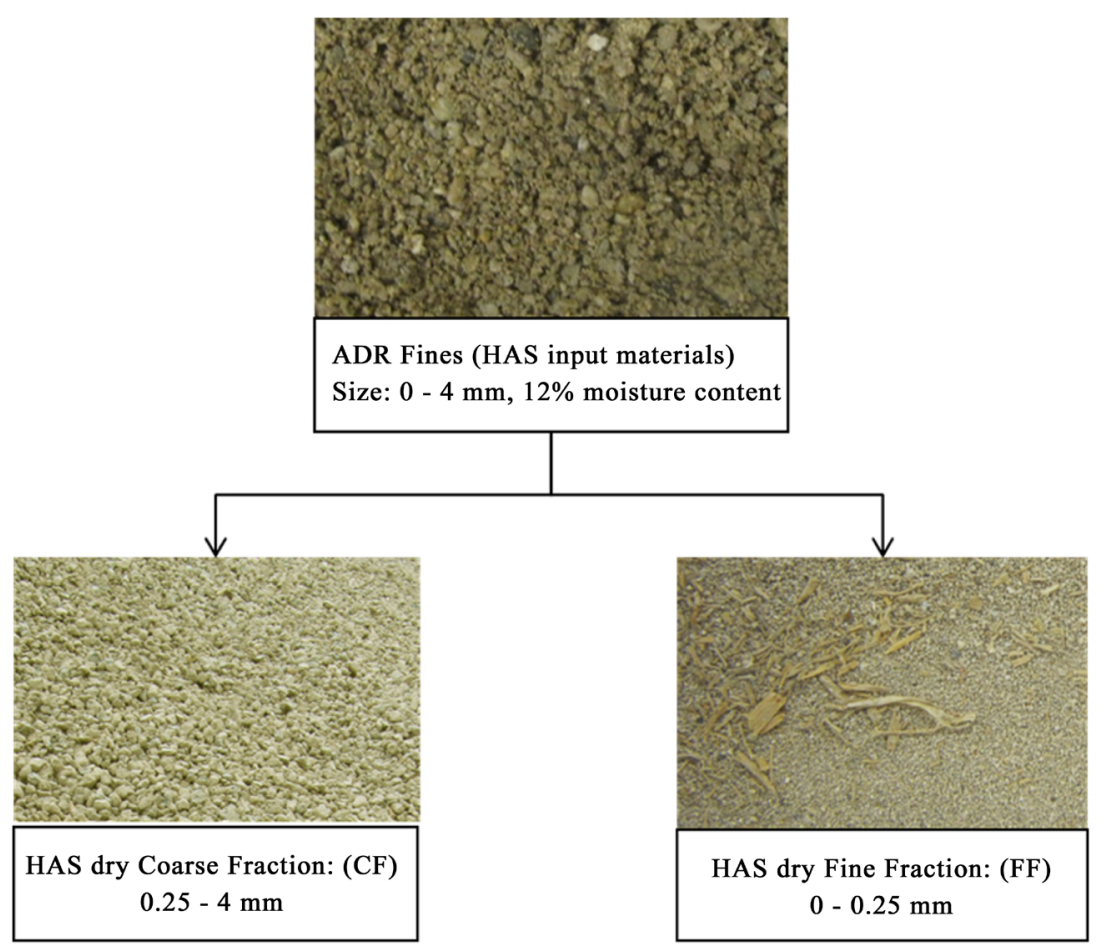

Figure 9. Input and outputs of HAS. 0 - $4 \mathrm{~mm}$ ADR Fines is heated and separated to CF: $0.250-4 \mathrm{~mm}$ and FF: 0 - 0.250 $\mathrm{mm}$. Depends on the temperature the wood is burnt or concentrated into FF.

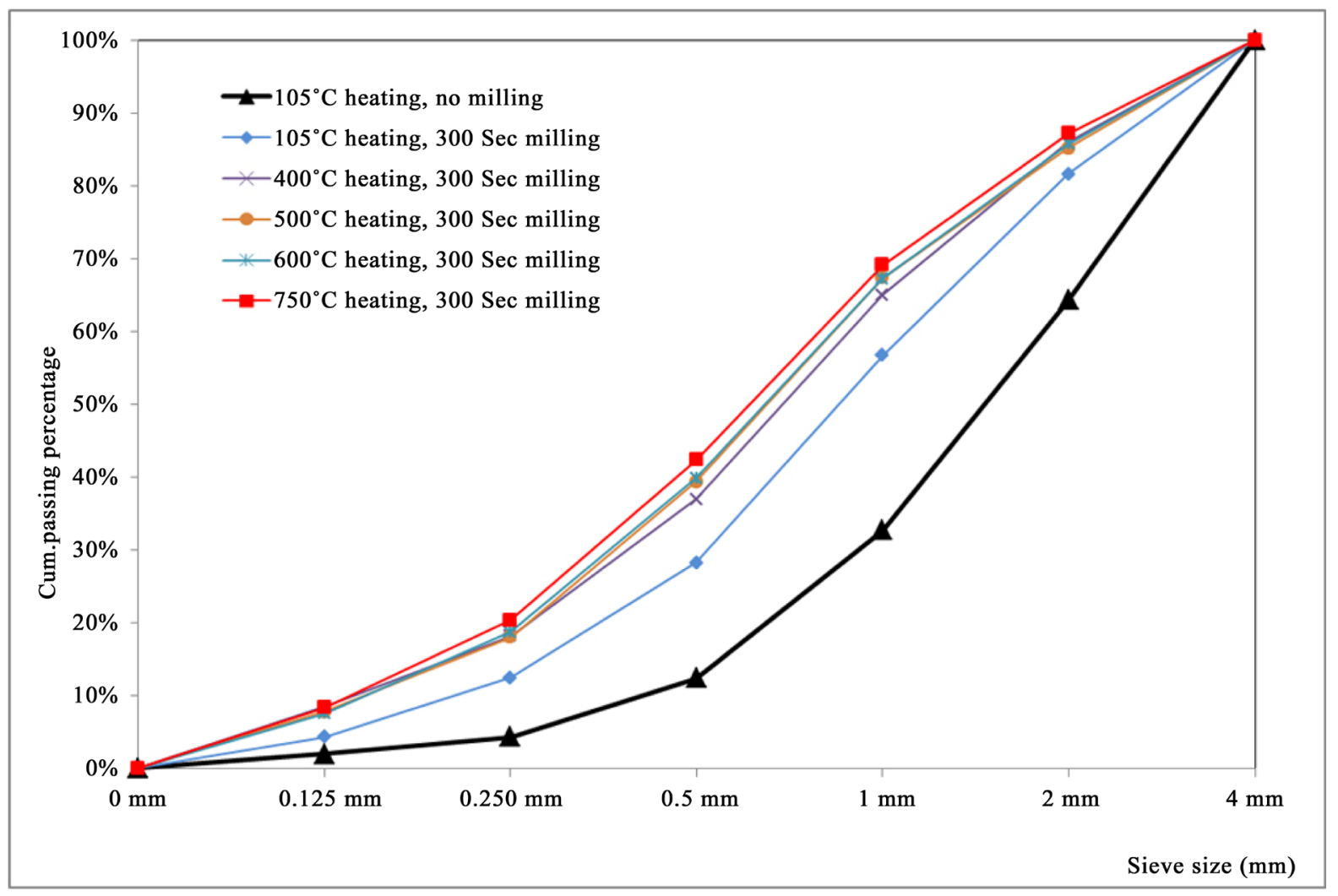

Figure 10. Particle size distribution of mill out-put while the milling time is constant at 300 second and mill input comes from different heating temperature in HAS. 
treated at different temperature by HAS and milled for 300 seconds. It is shown that the products size distributions moved towards the finer size range as the temperature increased. The same trend happens with increasing milling time at fixed heating temperature (for example at $750^{\circ} \mathrm{C}$ ) (see Figure 11). As mentioned previously, one of the main aims of this study is to investigate the effect of heating and grinding on the production of $0-0.250$ $\mathrm{mm}$ fines which is mostly hardened cement rich. 2D contour and surface plot of weight percentage with respect of milling time and heating temperature in Figure 12 shows the positive influence of both parameters on increasing the mass of this fraction. Using the contour plot one can optimize the heating temperature and milling time for producing a specific amount of $0-0.250 \mathrm{~mm}$ fines at minimum cost. Ball Milling is usually a costly and an inefficient process in terms of energy requirements. Table 1 presents the costs of ball milling for both laboratory and industrial scale operations. The expected amount of CF for milling in an industrial scale is around 30 tons per hour (if ADR is run at 100 tons per hour). Changing the residence time from 300 to 90 seconds, while the throughput is constant at 30 tons per hour, demands a ball mill with a shorter length. Thus, the total cost of milling drops significantly (see Table 1).

The experimental results in Figure 13 confirm that for production of a constant amount of fines $(0-0.25 \mathrm{~mm})$, the heating temperature can be increased to achieve reduced milling time accordingly. Decreasing the milling time is advantageous because less unwanted fine silica will be produced. This silica presents a health risk and it limits the hardened cement concentration. In addition, according to Table 1, with reducing the residence time, the cost of milling reduces significantly.

In addition to the cost, the quality of the products is another important factor to ensure an effective recycling process. For the quality aspects, we considered the removal of contaminants, grading of the products, density and water absorption of the produced sand and finally the amount of hardened cement concentrated in FF. Many organic substances such as wood are unstable in concrete when submitted to drying and wetting or freezing and thawing [18]. In order to enhance the quality of the recycled sand for high grade applications, wood and plastic must be removed. Experimental results based on Loss On Ignition (LOI) test show that this removal is complete

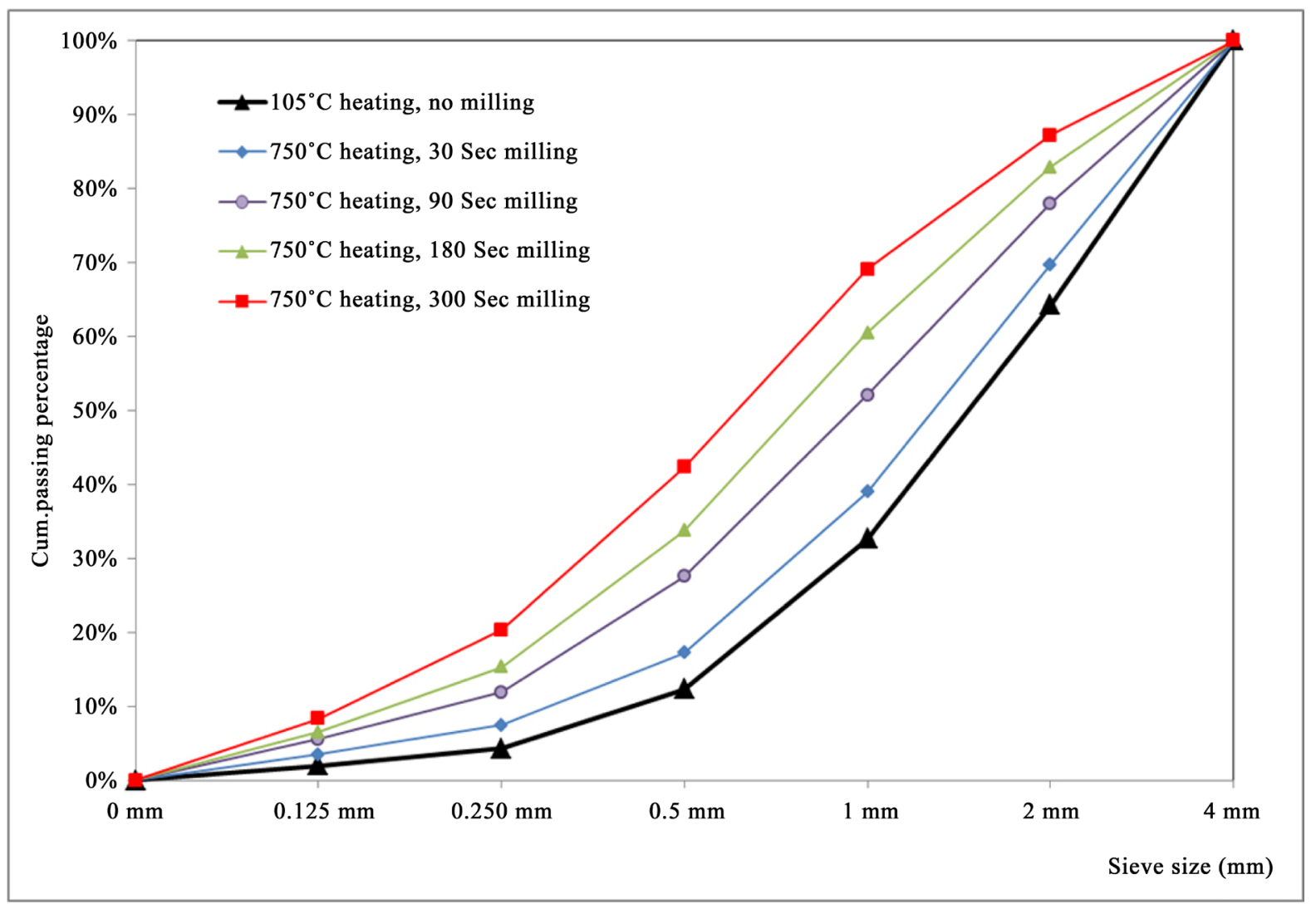

Figure 11. Particle size distribution of mill out-put while the milling time is variable and mill input come from constant heating temperature in HAS. 

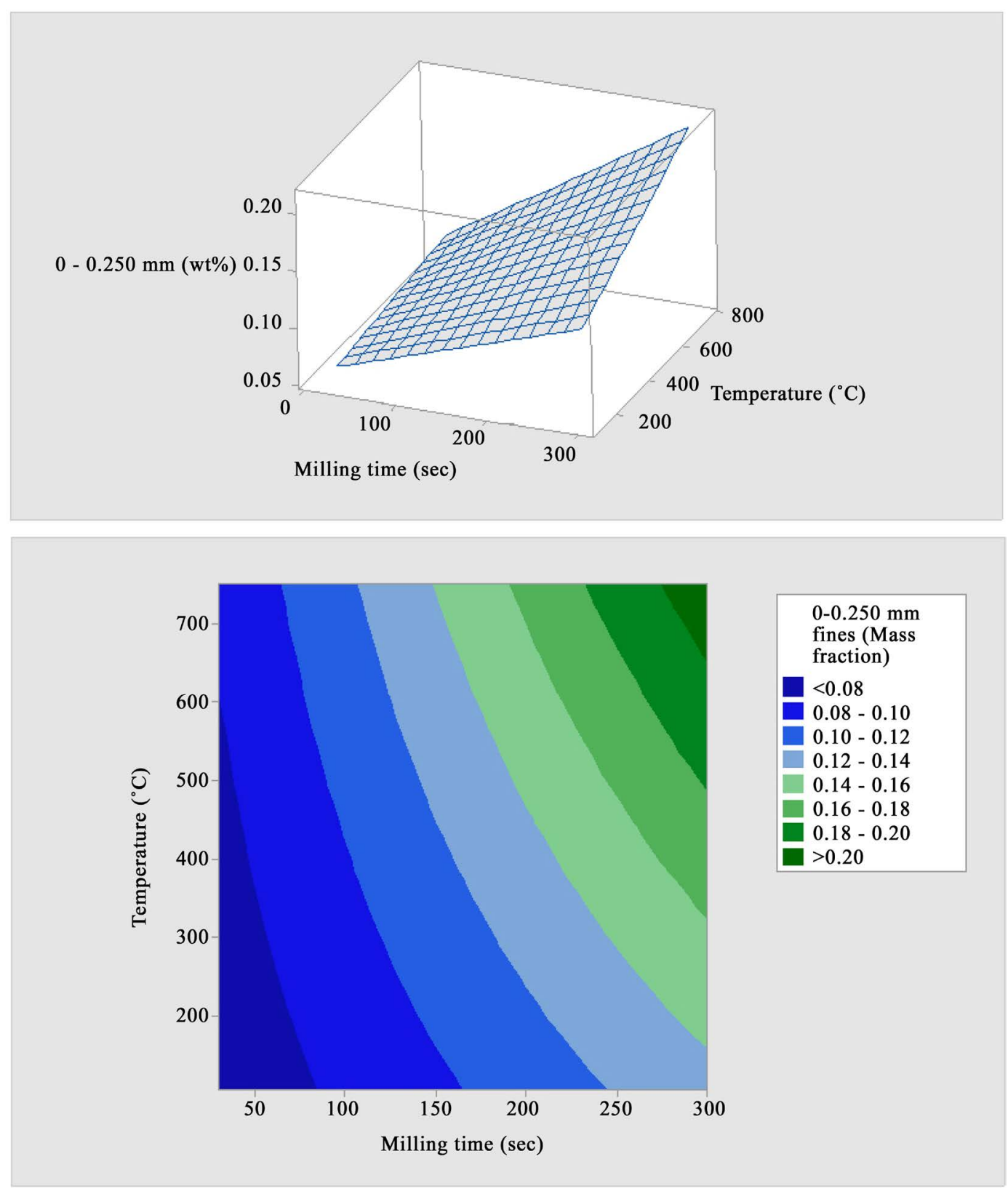

Figure 12. Surface and contour plot for $0-0.250 \mathrm{~mm}$ fines production while varying the temperature in HAS and timing in BM.

Table 1. The cost estimation for laboratory and industrial scale ball milling.

\begin{tabular}{|c|c|c|c|c|c|c|c|c|c|c|c|c|c|c|}
\hline Scale & 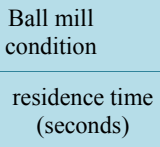 & $\begin{array}{r}\text { Capacity } \\
\text { (kg/hour) }\end{array}$ & $\begin{array}{l}\text { power } \\
(\mathrm{kW})\end{array}$ & $\begin{array}{c}\text { energy cost } \\
(€ / \text { ton })\end{array}$ & $\begin{array}{l}\text { wear } \\
(€ / \text { ton })\end{array}$ & $\begin{array}{c}\text { investment } \\
\text { cost }(€)\end{array}$ & $\begin{array}{l}\text { capital cost } \\
\text { in } € / \text { ton }\end{array}$ & $\begin{array}{c}\text { diameter } \\
\text { of ball mill (m) }\end{array}$ & $\begin{array}{c}\text { length of } \\
\text { ball mill (m) }\end{array}$ & $\begin{array}{l}\text { speed } \\
(\mathrm{rpm})\end{array}$ & $\begin{array}{l}\text { speed } \\
(\mathrm{rph})\end{array}$ & $\begin{array}{l}\text { weight of } \\
\text { balls }(\mathrm{N})\end{array}$ & $\begin{array}{l}\text { height of } \\
\text { drop (m) }\end{array}$ & $\begin{array}{l}\text { total cost } \\
(€ / \text { ton })\end{array}$ \\
\hline $\mathrm{Lab}^{*}$ & 300 & 192 & 0.23 & 0.12 & 0.12 & 4294 & 4.97 & 0.6 & 0.3 & 45 & 2700 & 600 & 0.5 & 5.20 \\
\hline $\operatorname{Ind}^{* *}$ & 300 & 30,000 & 36.00 & 0.12 & 0.12 & 116,281 & 0.84 & 1.2 & 3 & 22.5 & 1350 & 96,000 & 1.0 & 1.08 \\
\hline $\mathrm{Lab}$ & 90 & 640 & 0.23 & 0.04 & 0.04 & 4294 & 1.49 & 0.6 & 0.3 & 45 & 2700 & 600 & 0.5 & 1.56 \\
\hline Ind & 90 & 30,000 & 10.80 & 0.04 & 0.04 & 53,167 & 0.38 & 1.2 & 1 & 22.5 & 1350 & 28,800 & 1.0 & 0.45 \\
\hline
\end{tabular}




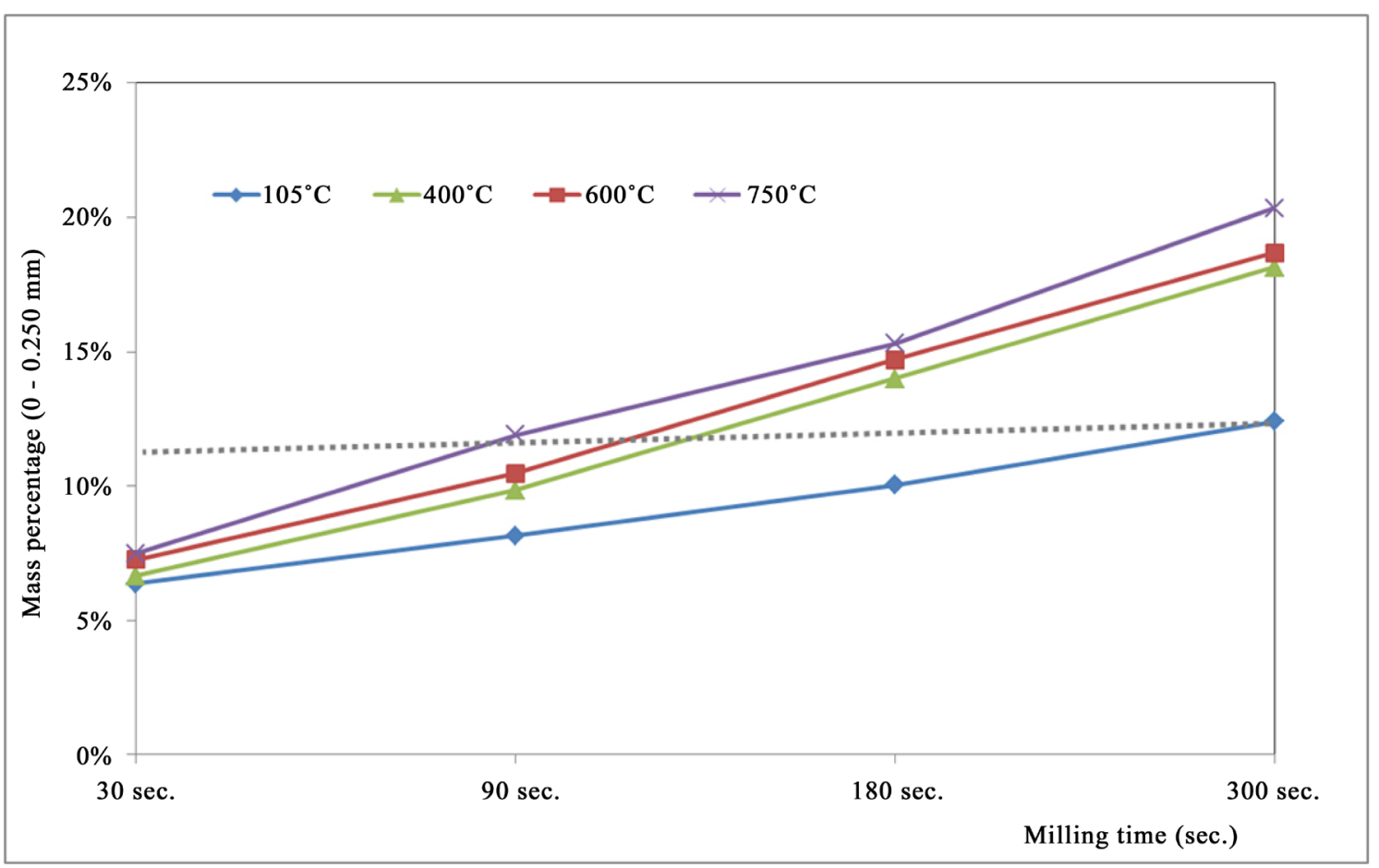

Figure 13. Reduction in the milling time by increasing the temperature for production the similar amount of $0-0.250 \mathrm{~mm}$.

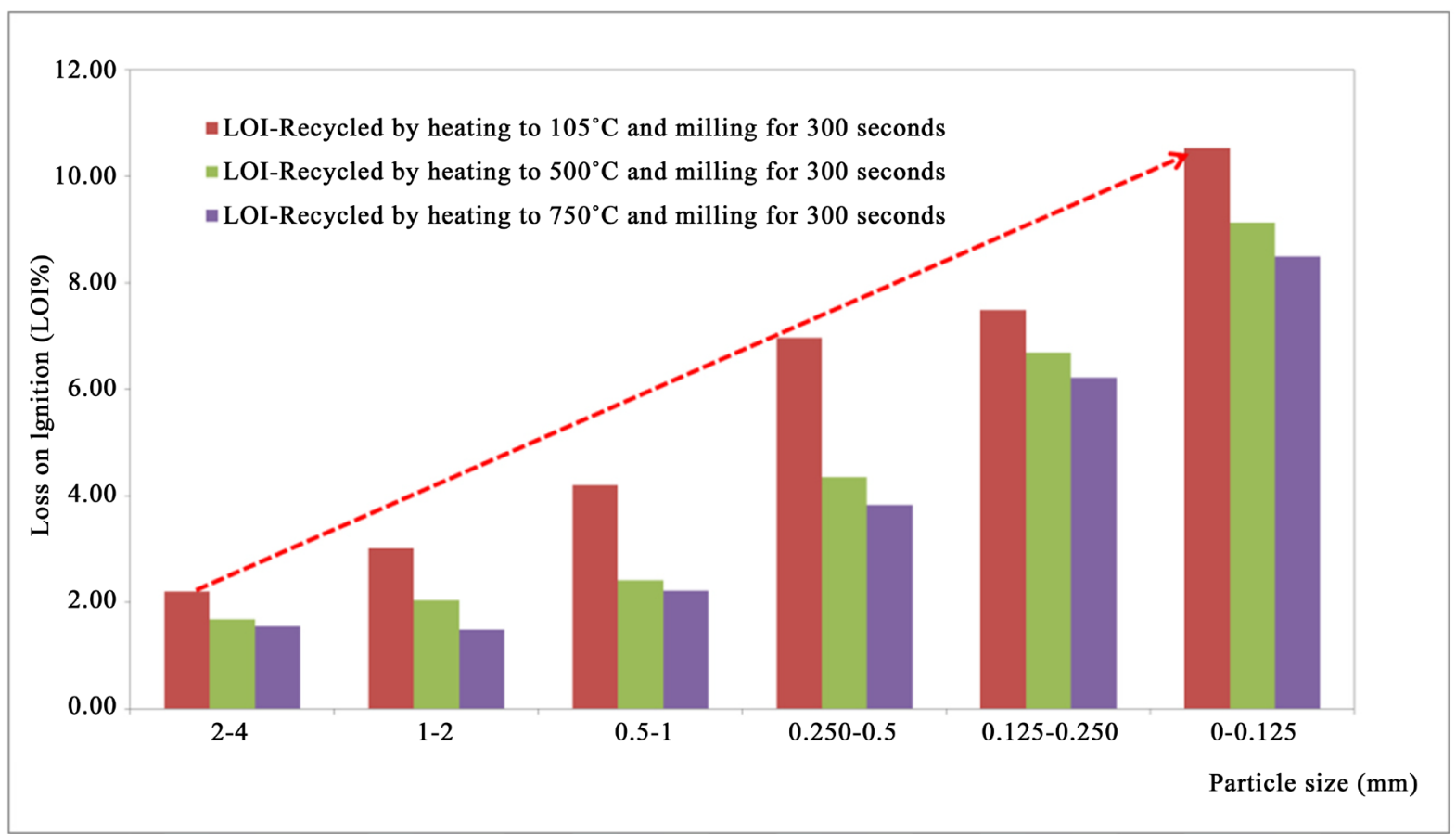

Figure 14. LOI of each fraction as an indication for their wood content.

at $500^{\circ} \mathrm{C}$. The LOI test consists of heating of some grams of each fraction at $950^{\circ} \mathrm{C}$ and allowing organic substances to escape until its mass stops changing. Figure 14 shows that the difference in LOI between materials recycled at $500^{\circ} \mathrm{C}$ and $750^{\circ} \mathrm{C}$ is small. It is therefore concluded that for the removal of organic materials, heating for 30 seconds at $500^{\circ} \mathrm{C}$ is sufficient. Amount of LOI has an inverse relation with the particle size. In general, the amount of LOI increases with decreasing the particle size. It indicates higher concentration of materials like 
wood in finer fractions.

Another important quality aspect is the grading of the produced sand. Recycled sand should be well-graded and comply with the standards applied in the market. The grading limit for $0-4 \mathrm{~mm}$ sand existing in the Dutch market is illustrated in Figure 15 (Max and Min black lines). According to this figure, it is clear that the particle size distribution of the recycled sand heated to $500^{\circ} \mathrm{C}$ and milled for 90 seconds, is well within the limiting curves. Considering the current prices in the Dutch market, it is estimated that the selling price for the cementitious part $(0-0.250 \mathrm{~mm})$ and sandy part $(0.250-4 \mathrm{~mm})$ would be $6 € /$ ton and 5 to $7.5 € /$ ton respectively. The original AF fractions, with limited applicability in the production of new building materials, have the value of ca $1 € /$ ton.

Density and water absorption of aggregates are usually considered as being inter-related, showing an almost linear inverse relationship [2]. It is well-known that recycled aggregates or sand have lower density and consequently higher water absorption than the natural ones due to the attached hardened cement. Figure 16 shows the density of each particle size resulting from $500^{\circ} \mathrm{C}$ and 300 seconds milling, measured using the He pycnometer. As it can be seen particles smaller than $0.125 \mathrm{~mm}$ have a density of $2.24 \mathrm{gr} / \mathrm{cm}^{3}$, which is the lowest density among all the particle sizes. The densities have then a slightly increasing trend with particle size to $2.62 \mathrm{gr} / \mathrm{cm}^{3}$ for $2-4 \mathrm{~mm}$ particles. Previously Florea et al. [20] reported a lowest density of $2.45 \mathrm{gr} / \mathrm{cm}^{3}$ for $0-0.63 \mathrm{~mm}$ fraction and a density of 2.61 for $2-4 \mathrm{~mm}$ recycled sand. Using a linear correlation equation between the density and water absorption of recycled aggregate expressed by de Juan et al. [21] the amount of water absorption for the same fractions are estimated and shown in Figure 17. Maximum water absorption for fine recycled aggregates is recommended to be in the range of $3 \%-13 \%$ in the most and least restrictive standards [2]. Water absorption shown in Figure 17 satisfies well the most restrictive standard of JIS A 5021. In the market, recycled sand with water absorption less than $5 \%$ is usually ranked in a good level of quality.

\subsection{Proportion of Hardened Cement and Sand in the Recycled Fractions}

In general, crushed concrete fines contain mostly hardened cement and $\alpha$-quartz (sand) originated from broken aggregates [20]. XRF analysis was carried out on various size fractions after the recycling procedures. The content of $\mathrm{SiO}_{2}$ measured by XRF ( $\left(\mathrm{SiO}_{2} \%\right)$ XRF) in fines is the sum of $\alpha$-quartz (sand) and $\mathrm{SiO}_{2}$ from the cement hydration products. The content of $\mathrm{SiO}_{2}$ from hydration products can be traced back from the chemical compo-

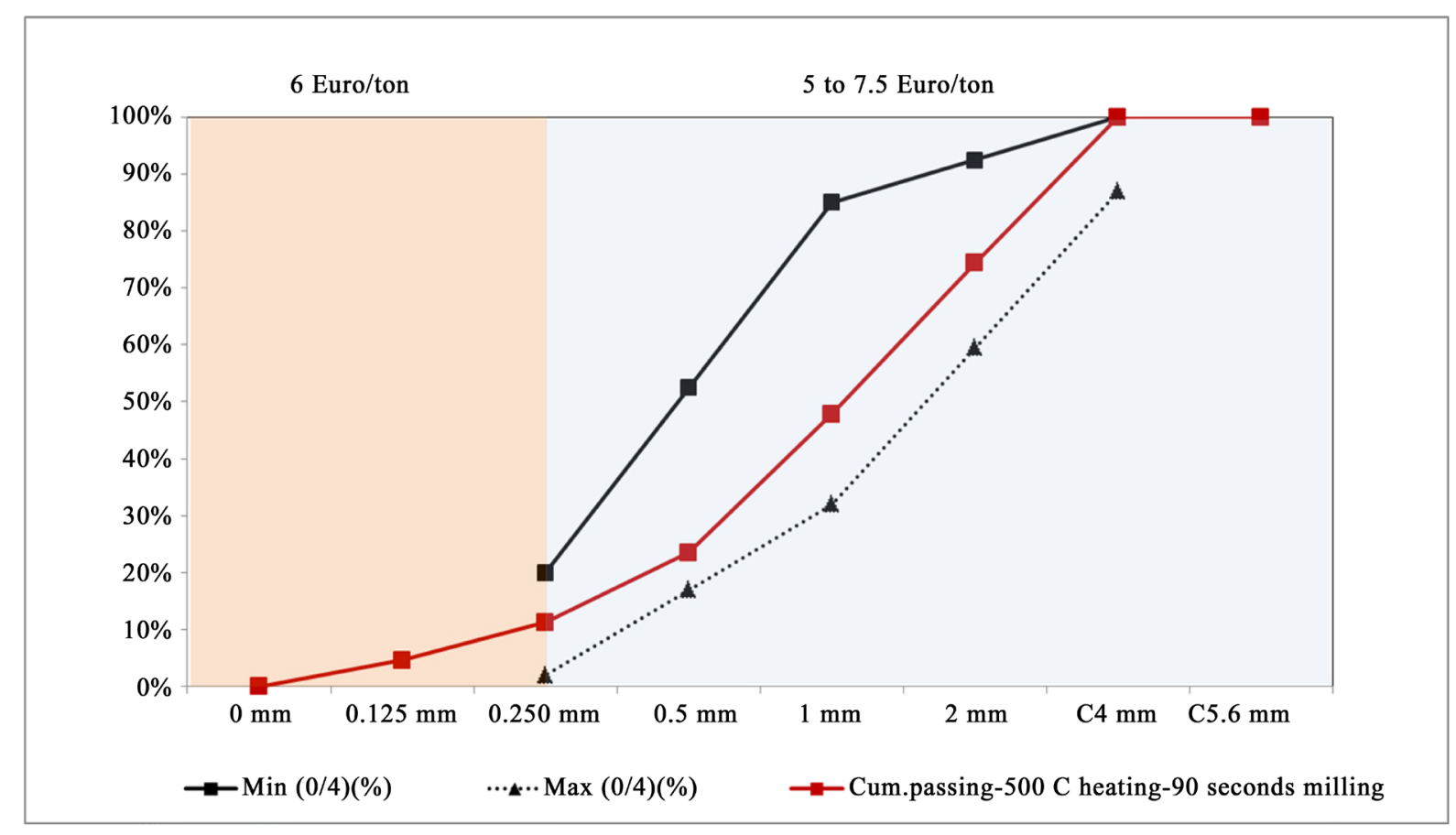

Figure 15. The grading requirements for $0-4 \mathrm{~mm}$ sand (Max and Min lines) in the Dutch market compared to the grading of the recycled products. 


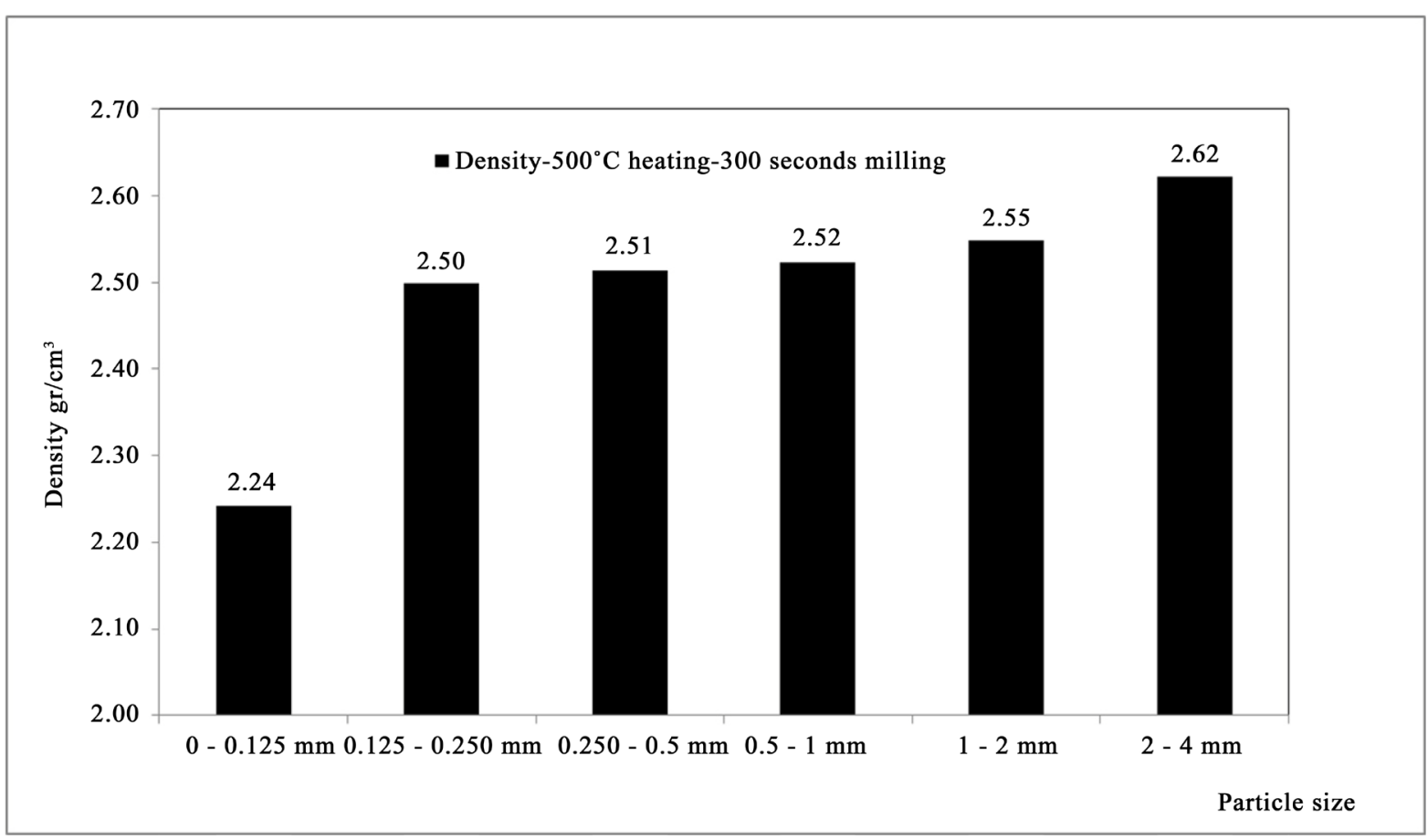

Figure 16. Densities of all fractions obtained from recycling process at $500^{\circ} \mathrm{C}$ and 300 seconds milling.

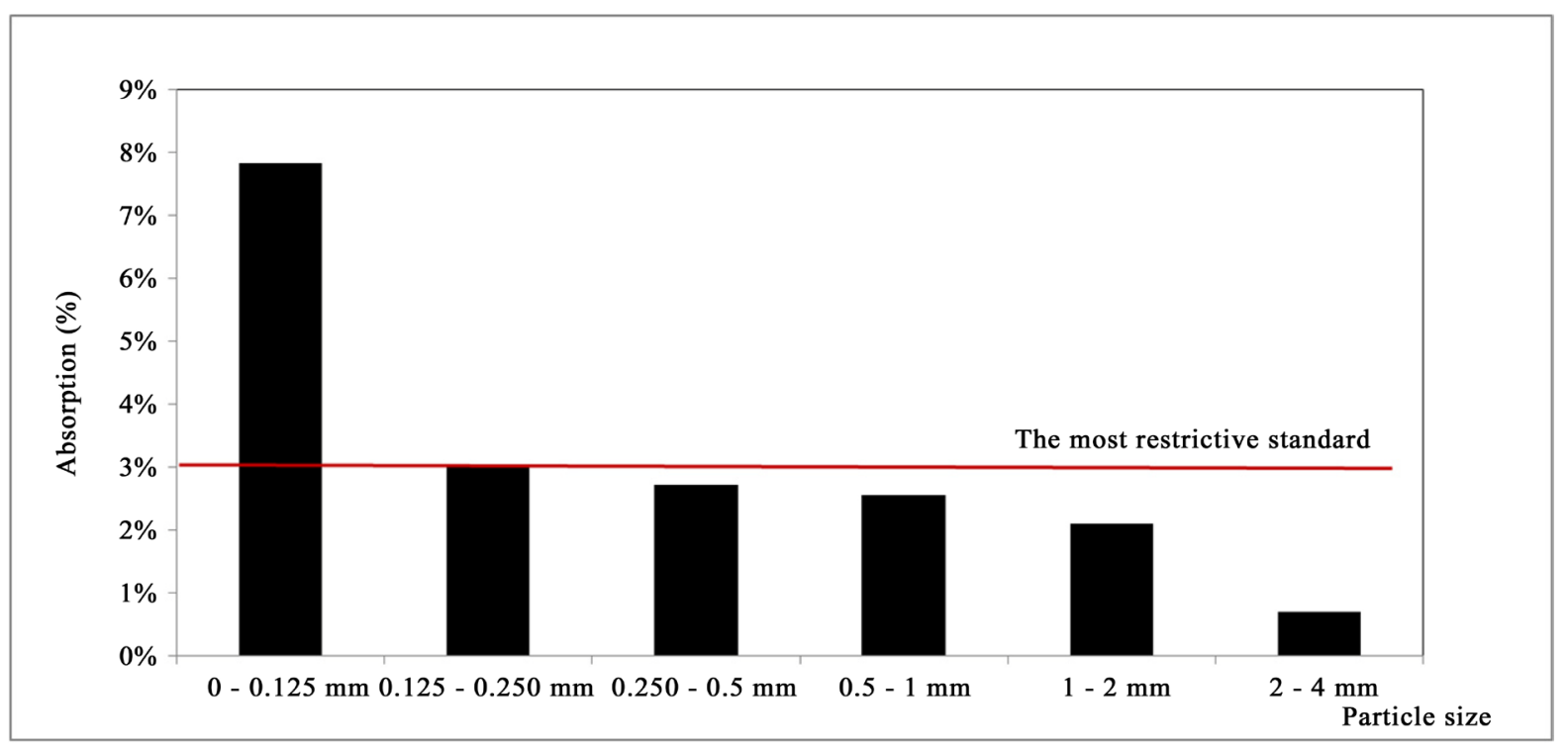

Figure 17. Estimated water absorption of all fractions obtained from a recycling process at $500^{\circ} \mathrm{C}$ with 300 seconds milling.

sition of cement (( $\left.\left.\mathrm{SiO}_{2} \%\right) \mathrm{CEM}\right)$. Using DSC analysis, it is possible to calculate the amount of $\alpha$-quartz in the recycled concrete aggregate fractions [19] [20].

The relationship between the parameters is expressed below [19]:

$$
\left(\mathrm{SiO}_{2} \%\right) \mathrm{XRF}=\left(\alpha \text {-quartz\%) DSC }+(1-(\alpha \text {-quartz\% }) \mathrm{DSC}) \cdot\left(\left(\mathrm{SiO}_{2} \%\right) \mathrm{CEM}\right)\right.
$$

In the referred research it is reported that the error between XRF results and TG-DSC is relatively low (under $3 \%$ ). According to the evidence received from the demolished buildings in C2CA project, the type of cement in the utilized old concrete was CEMIII/B. Considering a typical chemical analysis of CEMIII/B received from ENCI, Netherlands, not taking into account possible slight changes in the composition of cement during the 
time, the amount of $\left(\mathrm{SiO}_{2} \%\right)$ CEM was considered as $30 \%$. Using the amount of $\left(\mathrm{SiO}_{2} \%\right)$ XRF from the XRF analysis, it is possible to estimate the amount of hydrated cement and sand in various fractions.

Figure 18 (graphs (A)-(D)) shows the amount of hardened cement and sand in all considered fractions, coming from various heating and milling processes. According to the figure, there are some differences observed between analysed materials. Firstly it is illustrated that the bigger particle sizes are cleaner than the small ones in terms of hardened cement content. Comparing the coarser fractions in all graphs in Figure 18, it is clear that the fractions $1-2 \mathrm{~mm}$ and $2-4 \mathrm{~mm}$ processed at $105^{\circ} \mathrm{C}$ and no milling (see graph (A)), contain the highest amount of attached hardened cement. The $2-4 \mathrm{~mm}$ fraction in graph A contains $44 \%$ of hardened cement, while this number drops to $20 \%$ for the same particle size in graph $\mathrm{D}$ (processed at $750^{\circ} \mathrm{C}$ and 300 second milling). Considering the size $0-0.125 \mathrm{~mm}$ in all graphs in Figure 18, the effect of the recycling process on concentration of hardened cement in this fraction is obvious. To understand the effect of the milling (independent from heating) on the hardened cement content of each fraction, graph (A) and graph (B) in Figure 18 can be compared, and it is concluded that milling has an influence on the cleaning of the coarser fraction from hydrated cement and concentrating the cementitious powder into the finer fractions. By introducing the heat during the recycling, much cleaner sand $(0.250-4 \mathrm{~mm})$ is produced. Increasing the heating temperature to $750^{\circ} \mathrm{C}$ may cause the sandy part to get more brittle and results in an increment of the sand percentage in very fine fractions (graph (D)).

Figure 19 presents the cumulative distribution of hardened cement and sand based on the particle size distribution of the final output materials from the recycling process and hardened cement-sand content of each size fraction. According to Figure 19-graph (A) (processed at $105^{\circ} \mathrm{C}$ and no milling) just $6 \%$ recovery of the total hydrated cement (existing in $0-4 \mathrm{~mm}$ fraction) can be achieved for particles under $0.250 \mathrm{~mm}$. By adding the milling step (see graph (B)-Figure 19) the recovery rises to $19 \%$ for the particles smaller than $0.250 \mathrm{~mm}$ size. With heating at $500^{\circ} \mathrm{C}$ and $750^{\circ} \mathrm{C}$, the amount of cement recovery in particles under $0.250 \mathrm{~mm}$ raises to $34 \%$ and $39 \%$, respectively. Considering Figure 19 -graph (D) $\left(750^{\circ} \mathrm{C}\right.$ heating and $300 \mathrm{sec}$ milling), the cumulative recovery of hardened cement for fractions below $1 \mathrm{~mm}$ is $82 \%$, while this number drops to $32 \%$ for dry materials processed at $105^{\circ} \mathrm{C}$ and no milling (graph (A)). When comparing different graphs of Figure 19, in terms of the efficiency of recovering of hardened cement, it can be noticed that there is a slight difference between the percentage of the produced $0-0.250 \mathrm{~mm}$ at $500^{\circ} \mathrm{C}$ and $750^{\circ} \mathrm{C}$. Therefore, it seems more advantageous to keep the recycling temperature at $500^{\circ} \mathrm{C}$.

Table 2 shows a comparison among the chemical composition of ADR fines and some raw meal materials such as clay and limestone (in two different quality levels). In the same table, the chemical composition of the 0 $-0.125 \mathrm{~mm}$ produced within this study is added as well. A comparison between the numbers shows that the amounts of $\mathrm{CaO}, \mathrm{Al}_{2} \mathrm{O}_{3}$ and $\mathrm{Fe}_{2} \mathrm{O}_{3}$ in the produced $0-0.125 \mathrm{~mm}$ fraction are well comparable with the amounts in low-quality limestone (around $35 \mathrm{wt} \% \mathrm{CaO}$ ). The required heat energy for drying of one ton ADR fines is estimated to be $300 \mathrm{MJ}$. Based on the Ecoinvent database, $0.0716 \mathrm{~kg} \mathrm{CO}_{2}$ will be produced for the production of 1 MJ heat (if the fuel is gas) [22]. Therefore, the amount of $\mathrm{CO}_{2}$ emission resulted from heating of ADR fines for the production of 1 ton of hardened cement is estimated to be $108 \mathrm{~kg}$. On the other hand, the clinker emission factor is the product of the fraction of lime in the clinker multiplied by the ratio of the mass of $\mathrm{CO}_{2}$ released per unit of lime [23]. Thus, for the production of one ton of clinker, almost $344 \mathrm{~kg}$ of chemical $\mathrm{CO}_{2}$ will be released. A comparison between the aforesaid numbers shows that by reusing the cement paste from old concrete the release of the chemically bound $\mathrm{CO}_{2}$ will be reduced by a factor of three.

\section{Conclusions}

While at present crushed concrete fines accounts for a massive by-product of concrete recycling, construction industry has a limited tendency to use this material in new applications. On the other hand, the significant importance of preserving natural resources, reduction of $\mathrm{CO}_{2}$ emissions and considering crushed concrete fines as a valuable resource and not as a waste, are the main driving forces to develop a proper technology for recycling of crushed concrete fines into valuable products like hardened cement and clean sand. Solving the problems with crushed concrete fines is strongly associated with the removal of very small particles $(0-0.250 \mathrm{~mm})$ and contaminants. Considering the wet and sticky state of the crushed concrete fines, a heating step in the recycling process seems inevitable to make the process robust. In this study, a lab scale Heating-Air classification system (HAS) was designed and constructed. Laboratory experiments were carried out to investigate the influence of 

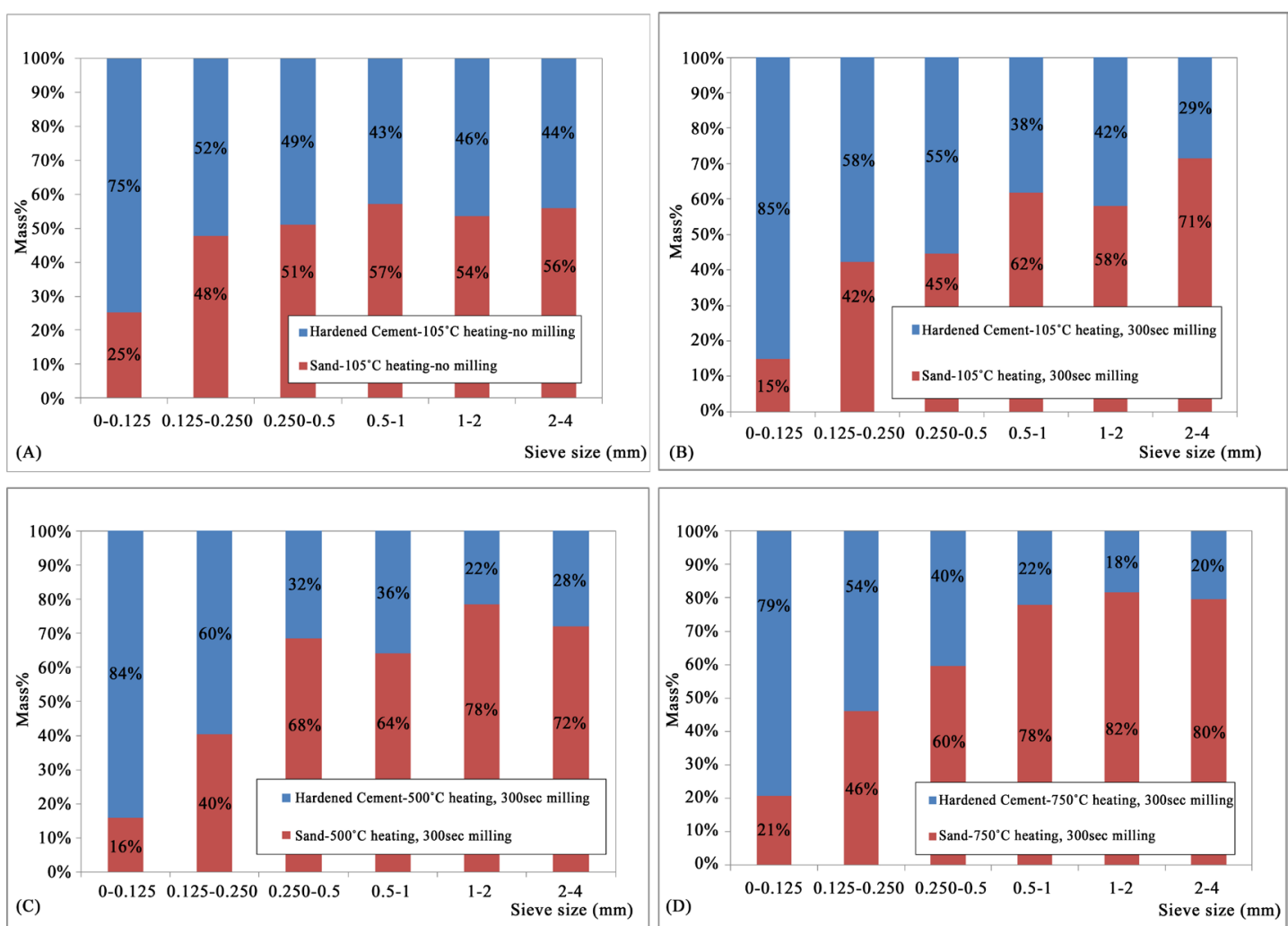

Figure 18. Composition of all recycled fractions divided into sand and hardened cement components for various recycling conditions.
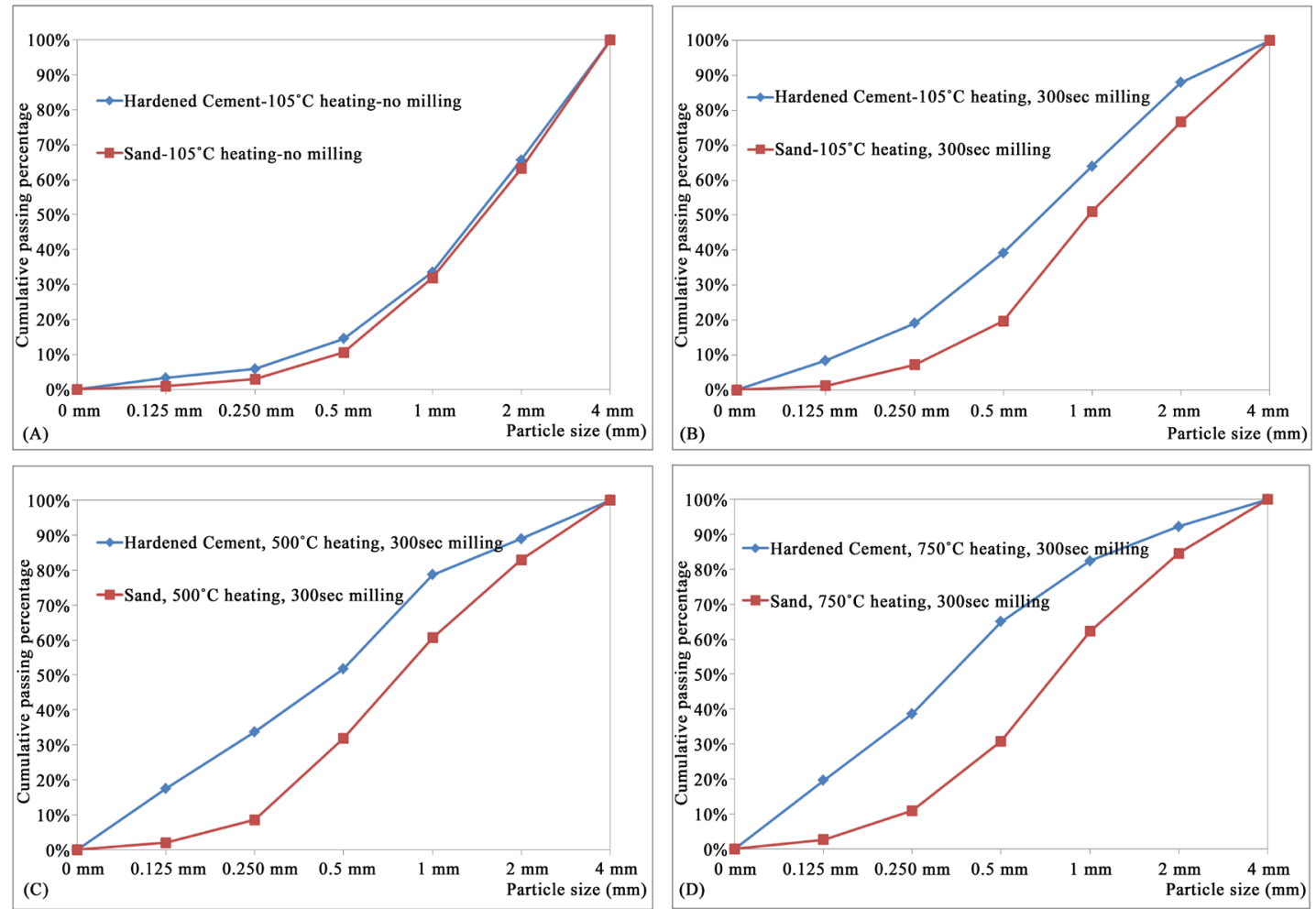

Figure 19. Cumulative distribution of the hardened cement paste and sand for various recycling conditions. 
Table 2. XRF values for ADR fines and FF in comparison to limestone and clay component.

\begin{tabular}{cccccc}
\hline Oxides & $\begin{array}{c}\text { ADR fines } \\
\text { directly used in } \\
\text { C2CA trial }\end{array}$ & $\begin{array}{c}\mathrm{FF}(0-0.125 \mathrm{~mm}) \text { resulted from } \\
\text { heating and grinding }\end{array}$ & Example Clay & $\begin{array}{c}65 \% \mathrm{CaCO}_{3} \text { (marl) Lime- } \\
\text { stone-low quality }\end{array}$ & $\begin{array}{c}95 \% \mathrm{CaCO}_{3} \\
\text { Limestone-high } \\
\text { quality }\end{array}$ \\
\hline $\mathrm{SiO}_{2}$ & 75.49 & 41.2 & 67.30 & 21.80 & 2.83 \\
$\mathrm{Al}_{2} \mathrm{O}_{3}$ & 4.57 & 6.42 & 9.00 & 5.48 & 0.69 \\
$\mathrm{TiO}_{2}$ & 0.23 & 0.41 & - & 0.26 & 0.03 \\
$\mathrm{MnO}$ & 0.13 & 0.13 & - & 0.03 & 0.03 \\
$\mathrm{Fe}_{2} \mathrm{O}_{3}$ & 1.64 & 2.97 & 4.30 & 1.86 & 0.28 \\
$\mathrm{CaO}$ & 11.24 & 35.16 & 7.30 & 36.60 & 53.00 \\
$\mathrm{MgO}$ & 1.23 & 1.79 & 2.00 & 0.87 & 0.61 \\
$\mathrm{~K}_{2} \mathrm{O}$ & 0.85 & 0.78 & 1.20 & 0.97 & 0.13 \\
$\mathrm{Na}_{2} \mathrm{O}$ & 0.43 & - & 1.40 & 0.13 & 0.04 \\
$\mathrm{SO}_{3}$ & 0.78 & 1.75 & 0.30 & 0.56 & 0.04 \\
$\mathrm{P}_{2} \mathrm{O}_{5}$ & 0.07 & - & - & 0.08 & 0.06 \\
$\mathrm{LOI}$ & 9.03 & 9.13 & 7.20 & 30.88 & 41.90 \\
\hline
\end{tabular}

different levels of heating and grinding on the hardened cement and sand recovery from moisturized and contaminated crushed concrete fines. Based on the results the following conclusions are drawn out:

- A combination of heat and air classification in HAS, results in a proper separation of finer $(0-0.250 \mathrm{~mm})$ from coarser fractions while it simultaneously weakened the cementitious bonding in the materials.

- Milling of the coarser output of HAS in a ball mill enhanced the liberation of the hardened cement.

- Heating of the materials to $500^{\circ} \mathrm{C}$ for a duration of 30 seconds in HAS, results in a significantly reduced milling time. Reduction in the milling time decreases the cost of milling and avoids the production of new fine silica.

- When comparing different heating temperatures in terms of the efficiency, recovery of hardened cement, sand and contaminants removal, $500^{\circ} \mathrm{C}$ is concluded as the most suitable temperature.

- The quality of materials from the proposed recycling process satisfies the market demands and existing standards.

- The amount of $\mathrm{CaO}$ in the recycled very fine fraction is comparable with the amount of $\mathrm{CaO}$ in low-quality limestone.

- By reusing the recovered $0-0.250 \mathrm{~mm}$ fraction instead of limestone in the cement kiln, the release of the chemically bound $\mathrm{CO}_{2}$ will be reduced by a factor of three. Based on the required chemical composition from the cement production industries, it is possible to change the cut size point for separation of the hardened cement rich from the sandy part.

On the basis of the encouraging results obtained and proven principles, a pilot scale set-up will be developed for high volume recycling of crushed concrete fines.

\section{Acknowledgements}

This research was funded by the European Commission mainly in the framework of the FP7 Collaborative project "Advanced Technologies for the Production of Cement and Clean Aggregates from Construction and Demolition Waste (C2CA)". Grant Agreement No. 265189. This research has partially received funding from the European Commission under the framework of the Horizon 2020 research and innovation program under grant agreement No 642085. The authors thank Ms. E. Di Domenica (MSc.) for her contribution to the study.

\section{References}

[1] http://cordis.europa.eu

[2] Pacheco-Torgal, F., Tam, V., Labrincha, J., Ding, Y. and de Brito, J. (2013) Handbook of Recycled Concrete and Demolition Waste. Elsevier, UK. http://dx.doi.org/10.1533/9780857096906

[3] Corinaldesi, V. and Moriconi, G. (2009) Behaviour of Cementitious Mortars Containing Different Kinds of Recycled 
Aggregate. Construction and Building Materials, 23, 289-294. http://dx.doi.org/10.1016/j.conbuildmat.2007.12.006

[4] Evangelista, L. and De Brito, J. (2010) Durability Performance of Concrete Made with Fine Recycled Concrete Aggregates. Cement and Concrete Composites, 32, 9-14. http://dx.doi.org/10.1016/j.cemconcomp.2009.09.005

[5] Etxeberria, M. and Vegas, I. (2015) Effect of Fine Ceramic Recycled Aggregate (RA) and Mixed Fine RA on Hardened Properties of Concrete. Magazine of Concrete Research, 67, 645-655. http://dx.doi.org/10.1680/macr.14.00208

[6] Lotfi, S., Deja, J., Rem, P., Mróz, R., van Roekel, E. and van der Stelt, H. (2014) Mechanical Recycling of EOL Concrete into High-Grade Aggregates. Resources, Conservation and Recycling, 87, 117-125. http://dx.doi.org/10.1016/j.resconrec.2014.03.010

[7] Rao, A., Jha, K.N. and Misra, S. (2007) Use of Aggregates from Recycled Construction and Demolition Waste in Concrete. Resources, Conservation and Recycling, 50, 71-81. http://dx.doi.org/10.1016/j.resconrec.2006.05.010

[8] Lotfi, S., Eggimann, M., Wagner, E., Mróz, R. and Deja, J. (2015) Performance of Recycled Aggregate Concrete Based on a New Concrete Recycling Technology. Construction and Building Materials, 95, 243-256. http://dx.doi.org/10.1016/j.conbuildmat.2015.07.021

[9] de Vries, W., Rem, P. and Berkhout, P. (2009) ADR: A New Method for Dry Classification. Proceedings of the ISWA International Conference, 12, 103-113.

[10] Lotfi, S., Di Maio, F., Xia, H., Serranti, S., Palmieri, R. and Bonifazi, G. (2015) Assessment of the Contaminants Level in Recycled Aggregates and Alternative New Technologies for Contaminants Recognition and Removal. Proceedings of the 15th Euroseminar on Microscopy Applied to Building Materials, Delft, 17-19 June 2015, 319-331.

[11] Xia, H. and Bakker, M.C.M. (2014) Reliable Classification of Moving Waste Materials with LIBS in Concrete Recycling. Talanta, 120, 239-247. http://dx.doi.org/10.1016/j.talanta.2013.11.082

[12] Serranti, S., Palmieri, R. and Bonifazi, G. (2015) Hyperspectral Imaging Applied to Demolition Waste Recycling: Innovative Approach for Product Quality Control. Journal of Electronic Imaging, 24, Article ID: 043003. http://dx.doi.org/10.1117/1.jei.24.4.043003

[13] Kleijn, R. (2012) Materials and Energy: A Story of Linkages. PhD Thesis, Leiden University, Netherlands, 135.

[14] Schoon, J., De Buysser, K., Van Driessche, I. and De Belie, N. (2015) Fines Extracted from Recycled Concrete as Alternative Raw Material for Portland Cement Clinker Production. Cement and Concrete Composites, 58, 70-80. http://dx.doi.org/10.1016/j.cemconcomp.2015.01.003

[15] Gastaldi, D., Canonico, F., Capelli, L., Buzzi, L., Boccaleri, E. and Irico, S. (2015) An Investigation on the Recycling of Hydrated Cement from Concrete Demolition Waste. Cement and Concrete Composites, 61, 29-35. http://dx.doi.org/10.1016/i.cemconcomp.2015.04.010

[16] Kwon, E., Ahn, J., Cho, B. and Park, D. (2015) A Study on Development of Recycled Cement Made from Waste Cementitious Powder. Construction and Building Materials, 83, 174-180. http://dx.doi.org/10.1016/j.conbuildmat.2015.02.086

[17] Kim, K.H., Cho, H.C. and Ahn, J.W. (2012) Breakage of Waste Concrete for Liberation Using Autogenous Mill. Minerals Engineering, 35, 43-45. http://dx.doi.org/10.1016/j.mineng.2012.05.011

[18] Hansen, T.C. (1990) Recycling of Demolished Concrete and Masonry. Taylor \& Francis, UK.

[19] Ning, Z. (2012) Thermal Treatment of Recycled Concrete Fines. Eindhoven University of Technology, Eindhoven.

[20] Florea, M.V.A. and Brouwers, H.J.H. (2013) Properties of Various Size Fractions of Crushed Concrete Related to Process Conditions and Re-Use. Cement and Concrete Research, 52, 11-21. http://dx.doi.org/10.1016/j.cemconres.2013.05.005

[21] De Juan, M.S. and Gutiérrez, P.A. (2009) Study on the Influence of Attached Mortar Content on the Properties of Recycled Concrete Aggregate. Construction and Building Materials, 23, 872-877. http://dx.doi.org/10.1016/j.conbuildmat.2008.04.012

[22] Weidema, B., Hischier, R., Althaus, H.J., Bauer, C., Doka, G., Dones, R. and Wernet, G. (2012) Code of Practice. Final Report Ecoinvent Data v2. 1 No. 2. Swiss Centre for Life Cycle Inventories, Duebendorf.

[23] Gibbs, M.J., Soyka, P., Conneely, D. and Kruger, M. (2000) $\mathrm{CO}_{2}$ Emissions from Cement Production. Good Practice Guidance and Uncertainty Management in National Greenhouse Gas Inventories. 